\title{
Concepções de Estado que atravessam movimentos sociais: análises provocativas
}

\section{Conceptions of State that permeate social movements: inciting analyses}

\section{Concepciones de Estado que atraviesan movimientos sociales: análisis provocativos}

\author{
Thalita Calmon Capelini* \\ Centro de Referência Especializado de Assistência Social (CREAS), Vitória, Espírito \\ Santo, Brasil
}

\author{
Gilead Marchezi Tavares** \\ Universidade Federal do Espírito Santo - UFES, Vitória, Espírito Santo, Brasil
}

\begin{abstract}
RESUMO
Partindo da problematização de um cenário de contestação política, o qual se espraiou pelo mundo ao final do ano de 2010, objetivamos analisar as concepções de Estado que perpassam movimentos sociais de luta por direitos. Para tanto, realizamos uma pesquisa-intervenção junto ao Centro de Defesa dos Direitos Humanos de Serra/ES. Durante um ano, participamos das suas Assembleias Gerais, registrando os acontecimentos, as trocas e nossas impressões em diários de campo. Realizamos, ainda, entrevistas com quatro militantes capixabas. As análises foram guiadas tanto pelos registros de diário de campo, quanto pelo material das entrevistas, que foram gravadas e transcritas. Durante o percurso da pesquisa-intervenção, destacamos aquilo que no terreno dos movimentos sociais encontrava-se endurecido: as concepções de Estado totalizador e transcendente, e de poder como sendo de propriedade e localizado no aparelho de Estado. Para compor nossas análises, trazemos as contribuições de Michel Foucault a respeito dos conceitos de governo e governamentalidade.
\end{abstract}

Palavras-chaves: aparelho de Estado, movimentos, cartografia, poder, governamentalidade.

\begin{abstract}
Based on a global context of political contestation, which began in the end of 2010, we intend to analyze how the State has been perceived by social movements that struggle for rights. Therefore, we conducted an intervention-research within the Human Rights Defense Center of Serra/ES, in which, for a year, we joined the General Assemblies, setting down the events, exchanges and our impressions on field diaries. Furthermore, we also interviewed four local activists. Both field diary notes and the material of the interviews, recorded and transcribed, were used to underlie the analyses. Along this article, we feature concepts that we believe are hardened in the realm of social movements: a totalizer and transcendent
\end{abstract}


State and the idea that power lies in the State apparatus and belongs to it. To compose the analyses, we bring the contributions of Michel Foucault concerning the concepts of government and governmentality.

Keywords: apparatus of state, movements, cartography, power, governmentality.

\section{RESUMEN}

A partir de la problematización de un escenario de contestación política que se esparció por el mundo a finales de 2010, tenemos como objetivo analizar las concepciones de Estado que atraviesan los movimientos sociales de lucha por derechos. Para eso, emprendemos una investigación-intervención junto al Centro de Defensa de Derechos Humanos de Serra/ES. Durante un año, participamos en las Asambleas Generales, registrando los acontecimientos, los cambios e nuestras impresiones en diarios de campo. Realizamos, además, entrevistas con cuatro militantes locales. Los análisis fueron conducidos tanto por los registros de diario de campo, como por el material de las entrevistas, que fueron grabadas y transcritas. Durante el recorrido de la investigación-intervención, destacamos lo que en el ámbito de los movimientos sociales se encontraba endurecido: las concepciones de Estado totalizador y trascendente, y de poder como siendo de propiedad y ubicado en el aparato de Estado. Para componer nuestros análisis, traemos las contribuciones de Michel Foucault con respecto a los conceptos de gobierno e gubernamentalidad.

Palabras clave: aparato estatal, movimientos, cartografía, poder, gubernamentalidad.

\section{Linhas que se misturam na composição de um campo problemático}

As provocações que tecemos neste artigo brotaram em meio a um cenário de contestação política, o qual se espraiou pelo mundo no final do ano de 2010, atravessando os anos subsequentes. Durante esse período, emergiram manifestações de todo tipo - Occupy Wall Street, Occupy London, Ocupa Rio, Primavera Árabe, Marcha da Liberdade etc. -, que convocavam todos a ocupar os espaços e tomar as ruas. Em diversos países, grupos articulavam-se, compondo movimentos de indignação ${ }^{1}$, como num vetor de contágio.

Os contextos, nuances e minúcias da onda de indignação pelo globo variavam de acordo com a localidade. Ou seja, os motivos de cada manifestação não necessariamente eram os mesmos nos diferentes países, mas havia um tom de descontentamento que tomava conta dos espaços e dos corpos. O cenário de efervescência mundial compunha, segundo Carneiro (2012), um quadro de

[...] desregulamentação global e perda de direitos sociais em nome da "flexibilização" que ampliou a nova camada social precarizada concentrada nos mais jovens. Esses jovens indignados da Europa, assim como os insurretos shabab ("jovens") do mundo árabe, são os que despertaram uma nova 
euforia política num mundo dominado pelos ideais de individualismo, de perpétua continuidade do cotidiano e de carência de projetos coletivos para o futuro (p. 13).

O efeito de 'contágio' diz respeito a um processo de co-emergências que propiciava, no decorrer dos protestos, a construção de vias de problematização possíveis e a desnaturalização das condições políticas, econômicas e sociais de existência. Nesse sentido, dava intensidade a determinados incômodos e suscitava articulações em torno de problemas específicos.

O contágio vislumbra uma articulação rizomática, por meio da qual os agrupamentos podem fazer emergir formas de coabitação descentralizadas, momentâneas, flexíveis e conexionistas, caracterizadas pelo seu grau de dispersão, por uma multiplicidade inconstante (Oliveira, 2007). Assim, como rizoma, o contágio é da ordem das multiplicidades, não começa nem conclui, mas encontra-se sempre no meio, entre as coisas. Refere-se a um mapa construído, mas sempre desmontável, reversível, com múltiplas entradas e saídas. "[...] o rizoma é um sistema a-centrado, não hierárquico e não significante, sem General, sem memória organizadora ou autômato central, unicamente definido por uma circulação de estados" (Deleuze \& Guattari, 1995, p. 32).

Havia nesses protestos, como escreveu Pelbart (2013), um "desejo coletivo", no qual as pessoas se engajavam. Desejo de ir às ruas, sentir o calor das multidões, vivenciar as redes, a coletividade, as diversidades e desejar aquilo que perpassava o comum, que constituía um bem comum a todos. Para o autor, o comum não corresponde a uma unidade, mas sim a um "[...] reservatório de singularidades em variação contínua" (p. 30) e deve ser concebido como um "[...] fundo virtual, como vitalidade social pré-individual, como pura heterogeneidade não totalizável [...]" (Pelbart, 2003, p. 30). Nesse sentido, a multidão pode ser

[...] pensada como uma multiplicidade heterogênea, nãounitária, não-hierárquica, acentrada e centrífuga. $\mathrm{Na}$ sua riqueza, ela é constituída pelo intelecto geral, afetividade, vitalidade a-orgânica etc. A multidão como figura subjetiva não identitária, que não delega poderes nem pretende conquistar o poder, mas desenvolver nova potência de vida, de organização, de produção. [...] com direções, inteligências e sensibilidades heterogêneas, que inventam não só modos próprios de produzir, de trocar, de habitar, de construir, mas também de relacionar-se, de afetar-se, de subjetivar-se, de protestar (Pelbart, 2003, p.133). 
Em tais ajuntamentos de pessoas e grupos, não eram as convicções partidárias, sindicais ou o pertencimento a movimentos sociais institucionalizados ${ }^{2}$ que se destacavam nas discussões. Não havia uma vinculação a uma organização específica e aparentemente não possuíam uma "racionalidade" definida.

$\mathrm{Na}$ ausência de lideranças claras, tais movimentos transversalizados e solidários forjavam ações que, localizadas num determinado ponto histórico, provocavam deslocamentos na participação popular frente à organização social vigente, produzindo, assim, uma nova cena política. Não se tratava "apenas de um deslocamento de palco - do palácio para a rua -, mas de afeto, de contaminação, de potência coletiva" (Pelbart, 2013, s/p.).

Diríamos que, nesses protestos, a história era constantemente arrancada de si mesma (Foucault, 1979), ganhando intensidades diversas, caminhos sinuosos e raros, seguindo a fomentar a vida nos cantos, nos vértices. Lá onde parecia que ela perdia a força ou o fôlego, a resistência se fazia.

Quando a vida parece inteiramente submetida aos desígnios do capitalismo global, a resistência passa a ser expressa como luta para reapropriá-la: libertar corpos, subjetividades, desejos e afetos, criar outras formas de vida, outras sinergias coletivas (Oliveira, 2007, p. 15).

As barricadas abriram fissuras na constituição dos saberes, trazendo questionamentos sobre "como viemos a nos tornar o que somos, como viemos parar onde estamos" (Veiga-Neto, 1995, p. 11-12), incitando-nos a (re)colocar em questão as práticas de protesto, a contraposição de forças no exercício do poder e as noções de Estado e governo.

As manifestações mundiais são aqui compreendidas como rasuras nos modos outrora instituídos de ser-pensar-agir, que nos auxiliam a tomar fôlego e retomar questões que pensávamos estarem esgotadas, superadas. A partir do indizível que enunciavam, voltamos o olhar aos movimentos sociais institucionalizados, na tentativa de desmanchar alguns contornos e durezas que se apresentam quando falamos em movimentos sociais e aparelho de Estado. Desse modo, neste artigo objetivamos problematizar as concepções de Estado que perpassam um movimento social institucionalizado, tecendo algumas análises provocativas.

Para tanto, nosso primeiro passo foi a aproximação com o Centro de Defesa dos Direitos Humanos da cidade de SerralES (CDDH) entidade que possui um longo histórico de lutas e conquistas em favor do respeito aos direitos humanos no Estado do Espírito Santo, tendo contribuído no processo formativo de grande parte dos militantes ativos do estado. 
O CDDH de Serra/ES surgiu na década de 1980, em um contexto de preocupação e mobilização contra a tendência política repressiva e marcada pelo descaso das governanças, que vinha se intensificando desde a instauração da ditadura militar em 1964. Criado inicialmente como Comissão de Direitos Humanos, em 1984, após o 3o Encontro Nacional de Direitos Humanos, ocorrido em Vitória/ES, o CDDH encontra suas bases nas ações dos monges combonianos que residiam na Serra (Paulino, 2009). Sua efetivação como Centro de Defesa dos Direitos Humanos se deu em 1988, estando o Centro pautado em princípios evangélicos e na Carta de Declaração Universal de Direitos Humanos (CDDH, 2003).

O Estatuto Social que rege o Centro o caracteriza como "pessoa jurídica de direito privado para fins não econômicos, de prazo de duração indeterminado" (CDDH, 2003, p. 1). A entidade não possui qualquer vínculo partidário, não adota credo religioso, presta serviços gratuitos não fazendo distinção de clientela.

$\mathrm{Na}$ busca de uma sociedade primada pela justiça, liberdade, igualdade de condições, pelo respeito às diversas culturas, ao ser humano e à natureza, o CDDH-SERRA numa inequívoca posição em favor dos desfavorecidos e marginalizados, tem por missão a DEFESA DA VIDA E DIGNIDADE HUMANA" (CDDH, 2003, p. 1).

A partir da aproximação com o $\mathrm{CDDH}$ e o conhecimento de sua história, militância e princípios, propusemos a construção do corpus de análise da pesquisa que originou este artigo por meio de duas técnicas: participação em assembleias mensais do Centro de Defesa dos Direitos Humanos (CDDH) de Serra/ES - que tiveram como fruto a produção de diários de campo - e a realização de entrevistas com quatro militantes - que foram gravadas e posteriormente transcritas. Escolhemos o primeiro entrevistado com base em seu envolvimento com $\circ \mathrm{CDDH}$ e coube a este indicar-nos outros personagens que poderiam ser entrevistados. Conforme assinala Sousa (2012),

Entrevistar exige tempo, paciência, e sobretudo estar aberto à escuta do que é inédito. Este é um grande desafio, pois frequentemente somos capturados em lógicas de repetição que nos fazem ouvir o que sempre ouvimos, perguntar o que sempre perguntamos e pensar o que sempre pensamos. O que é fundamental é recuperar a potência da questão de ousar adentrar os espaços estrangeiros que nos constituem e que permitem uma posição de invenção, de criação no movimento de entrevistar. (p. 87). 
Desse modo, as entrevistas foram guiadas de maneira aberta e informal, não seguiam um roteiro fixo pré-estabelecido, todavia possuíam alguns eixos norteadores - breve histórico de vida e inserção na militância, definição do aparelho estatal, avaliação da relação entre movimentos sociais e Estado, etc.

Cabe frisar que durante nosso percurso lançamos mão de uma prática cartográfica. Todavia, a cartografia, aqui, não foi utilizada apenas como metodologia, mas, sobretudo, como postura ético-política do pesquisar. Desse modo, não falamos em pesquisar sobre, mas pesquisar com. Apostamos que o campo de pesquisa se fez no decorrer do processo, sendo construído em conjunto com os personagens envolvidos. Nesse caso, não houve coleta de dados, mas sim produção de dados e de sentidos. Barros e Kastrup (2009) ressaltam que

[...] a política da escrita é sintonizada e coerente com a política de pesquisa e de produção de dados no campo. A política de não fazer dos participantes meros objetos da pesquisa e da construção coletiva do conhecimento revela-se aí com toda a sua força (p. 72).

Consideramos que a pesquisa e o próprio processo de escrita dizem respeito a uma tomada de posição que nos circunscreve num plano de responsabilidade ético-política por meio do qual estamos comprometidos sobremaneira com a afirmação da vida. Por tudo isso, é preciso estar atento aos efeitos produzidos por nossas práticas - de pesquisa, de vida. Em conjunto com Passos e Barros (2009), afirmamos que se trata de uma política da narratividade com a qual subvertemos o jogo estabelecido há tempos no fazer-pesquisa, tanto entre produção de saber e de mundo, quanto entre sujeito e objeto.

Desse modo, não houve uma etapa de construção de dados e outra de análise de dados. Esta é compreendida aqui como a problematização a cada passo da pesquisa, tracejando novos contornos em meio aos processos sociais em foco. É exatamente nessa medida que a produção de conhecimento é pensada como invenção de mundo e de sujeito (Kastrup, 1999). A atenção da pesquisadora à experiência da pesquisa manteve-se orientada por aquilo que emergia no campo a partir dos encontros com os participantes.

Este artigo configura-se como um ato de tomar a palavra em sua força política, tornando possível a produção de outros mundos, novas possibilidades, rompendo com a institucionalização de verdades científicas e práticas de assujeitamento daí advindas.

'Pinçando' as linhas que nos auxiliaram na composição do campo problemático desta pesquisa, destacamos que as manifestações globais em cena nos convocaram a pensar sobre o diagrama de 
forças constituintes do contemporâneo, que produz tanto o aparelho de Estado, quanto movimentos sociais. E ao olharmos para o "novo" que se escancara diante de nós, um movimento disforme, plural e caleidoscópico, decidimos voltar à atenção a um movimento social institucionalizado, buscando compreender como vem acompanhando tais transformações, como encampa tal cenário de mudanças disruptivas dos modos de luta.

Procuramos acompanhar os processos a partir dos quais se conformam ou se decompõem instituições e práticas, buscando cartografar micropolíticas em curso.

Macro e micromultiplicidades. De um lado, as multiplicidades extensivas, divisíveis e molares; unificáveis, totalizáveis, organizáveis; conscientes ou pré-conscientes - e, de outro, as multiplicidades libidinais inconscientes, moleculares, intensivas, constituídas de partículas que não se dividem sem mudar de natureza, distâncias que não variam sem entrar em outra multiplicidade, que não param de fazer-se e desfazer-se, comunicando, passando umas nas outras no interior de um limiar, ou além ou aquém (Deleuze \& Guattari, 1995, p.46)

Trata-se, sobretudo, de uma tentativa, dentre tantas possíveis, de um esboço - que não é estático ou permanente, estando sempre inacabado - desse emaranhado de linhas que compõem um momento singular e valioso. Frente a isso, nos colocamos a seguir as pistas que despontavam durante o trilhar da pesquisa, visando dar palavras e concretude às intensidades que pediam passagem.

\section{Desmanchando uma concepção majoritária do Estado: por um presente desejante de poros}

Inicialmente, gostaríamos de excursionar pela problemática do Estado, buscando delinear os territórios por onde caminharemos e a aposta que fazemos a partir das contribuições foucaultianas a respeito das noções de governo e Estado governamentalizado.

O Estado constitui figura latente nas práticas de movimentos sociais e, nesse sentido, por vezes, aparece como foco das ações articuladas. Ora para tensioná-lo, visando à garantia de direitos, ora para denunciá-lo quando violador deles. Em outros casos, para convocá-lo a somar forças na luta, ou até mesmo para transitar nele, ingressando em seus quadros.

“[...] o Programa [Estadual] de Proteção a Defensores de Direitos Humanos ${ }^{3}$, ele é um contraditório [...]. Porque, geralmente, o violador é o Estado. Se ele não é o violador, ele 
meio que encobre, né, os violadores. Porque, é, as empresas, né, recebem estímulos, recebem isenção de impostos e tal, pro Estado. E aí vem a sociedade civil, vem os defensores de direitos humanos que lutam contra o uso do agrotóxico, lutam contra a poluição dos rios pelas grandes empresas, que querem a reforma agrária para que a população tenha acesso à terra, à produção e tal, querem a demarcação de território... Tudo isso é um contraponto de quem financia o Estado, as eleições [...]. Então é complicado fortalecer um programa desse pro governo, né. É o que a gente achava que deveria ser uma coisa natural, e não é". (Entrevista 4)

"Uma fala me chama a atenção: "Estamos formando pessoas para assumir o Estado". Há uma linha tênue entre a espontaneidade dos movimentos sociais e a institucionalização. A sociedade civil organizada tem que caminhar por esses entremeios. Tensão e conflito. Ação, transformação e conservação".

(Diário de Campo 8, 23/03/2013)

“[...] Muitos militantes foram ocupar cargos, ou foram pro legislativo, e esse grupo que era militante começou a ser dirigente também. $E$ isso foi porque a gente era confiante na mudança, acreditava, tinha um horizonte político". (Entrevista 1)

No trilhar da pesquisa, muitas vezes esbarramos com a problemática do Estado. Entre conversas, vivências no $\mathrm{CDDH}$ e entrevistas com militantes, questões que atravessam sutilmente esse movimento social ganhavam, cada vez mais, visibilidade. Experienciar articulações, as composições das práticas e discursos em ato, levounos a delinear algumas questões e consideramos que nos debruçarmos sobre as mesmas - ou melhor, derramarmo-nos por entre elas - pode ser fundamental na oxigenação do presente, buscando porificá-lo e, até mesmo, forjar nele certa porofilia presente desejante de poros. Porosidade que concerne a uma abertura às trocas, aos fluxos e aos processos em curso. Poros, por sua vez, que sustentam a vida como meio aberto, processo inacabado, por entre os quais deslizam as intensidades, provisoriedades e o inesperado. Nesse sentido, oxigenar o presente compreende pontilhar contornos outrora instituídos, compondo com outros agenciamentos, linhas moleculares ou de fuga ${ }^{4}$, que "[...] 
traçam pequenas modificações, fazem desvios, delineiam quedas ou impulsos [...]" (Deleuze \& Parnet, 1998, p.147).

No bojo desse movimento social, como se está compreendendo o Estado? 'O que é' o Estado? É possível e estratégico defini-lo de maneira estanque? Tal definição se coloca a serviço de quais interesses, ajuda ou atrapalha na luta por direitos? Por outro lado, seria possível pensar o Estado como uma composição de forças? De onde se parte partimos quando se fala em "governo"? Quais ferramentas nos auxiliam a pensar o Estado e os movimentos sociais na contemporaneidade?

Nas assembleias do CDDH, vislumbramos que colocar em pauta a defesa/garantia de direitos, implicava falar sobre o Estado. Nas entrevistas, ao falarmos dos percursos de militância de cada um, conversávamos também sobre o Estado. A todo o tempo e momento, discutir o movimento social incutia-nos pensar sobre o Estado. Entretanto, de que Estado se fala? Trata-se de uma ideia, uma conjectura, um transcendente, um topos político, um emaranhado de práticas?

Nesse aspecto, sobressaíam dicotomias, visões dualistas de Estado e movimentos sociais, sociedade civil e governo, práticas de militância e práticas de Estado. Ou se pertence ao Estado, ou se pertence aos movimentos sociais. Ou você é militante, ou é governista. Ou você integra os quadros políticos do Estado, ou constitui a sociedade civil organizada. Coisas, papéis, atribuições, compromissos, cargos etc., que em uma presumida "essência" divergem, constituindo forças opositoras que se digladiam, se excluem mutuamente, não se misturam.

"Primeiro que, as pessoas que 'tavam na frente do movimento social e que foram convidadas para fazer parte de algum cargo no governo, não conseguem fazer, assim... Uns sim. Vão pra lá, sabem que são Estado e fazem papel de Estado. Outros ficam meio perdidos entre: eu sou agora Estado ou continuo sociedade civil? Então, isso dificulta um pouco a relação, mesmo, desses... Com a sociedade civil que ficou organizada, com os que estão no Estado. E aí, até hoje nós temos pessoas que estão há anos no Estado, mas, porque passaram pela sociedade civil, não conseguem se colocar no Estado no seu todo. Se coloca como Estado, mas parece que quer ficar bem com a sociedade civil e tem horas que diz: "Não, aqui eu 'tô como sociedade civil". Não tá, porque tá lá representando o Estado, né..." (Entrevista 4)

Nota-se que, por vezes, perpassa a militância - frisando que isso não diz respeito a um indivíduo ou a um grupo específico que pensa e age de determinada forma, mas refere-se a um corpo de discursos e 
práticas que compõe um modo de ser/fazer militância e movimentos sociais, ganhando visibilidade e produzindo efeitos no tecido social uma compreensão totalizadora do Estado como algo já dado, préconcebido, fechado em si mesmo e descolado das práticas preconizadas pela sociedade civil. Muitas vezes, as falas dão pistas de um entendimento do Estado e dos movimentos sociais como polos diametralmente opostos, que operam continuamente por racionalidades divergentes, sendo também constituídos por naturezas distintas.

“E aí eu tô num lugar que não é nem Estado... Tem hora que eu estou as duas coisas mesmo, assim. Porque é um Programa que faz a gestão de uma política pública, muita gente acha que eu sou Estado, que eu devo me comportar como Estado e eu não consigo ser Estado. Eu estou e sou sociedade civil, mesmo que eu esteja fazendo a gestão de uma política pública. Entendeu? Então, assim, se eu tiver que fazer - e mesmo se eu estiver Estado eu tinha que fazer isso também, né - todas as críticas, todas as nossas análises para corrigir e para reivindicar do Estado o que é necessário pra garantir a realização da política pública, eu vou fazer. E algumas pessoas não conseguem ter essa dimensão." (Entrevista 4)

Parece haver um estrangulamento do movimento social nesse ponto. Perdemos o fôlego quando esbarramos nessas definições, ou prédefinições. São questões de vértice, com arestas não aparadas, que nos aprisionam e cerceiam uma multiplicidade possível. As ferramentas teóricas acionadas quando falamos em movimentos sociais e Estado acabam contribuindo para que esse hiato perdure. Destacamos, nesse aspecto, o investimento em uma determinada forma de compreender o poder e o modo como esse conceitoferramenta é operado no bojo da relação entre movimentos sociais e Estado, pautando-se em uma visão maniqueísta e reificante, na qual algo ou alguém detém o poder em detrimento de outrem, que se encontra aquém e sendo, por isso, subjugado.

Foucault (1995) ressalta a importância de conhecermos as condições históricas nas quais se tornam possíveis os discursos do tempo em que vivemos, forjando-se uma consciência histórica do presente. No movimento de colocar o presente em análise, Foucault (1995) propõe que o poder não se restringe, meramente, às técnicas de exploração, dominação e sujeição, embora tais técnicas possam compor a estratégia do poder num dado momento. Ao mesmo tempo, ele não é da ordem da posse - algo como uma substância misteriosa ou um tesouro que se detém -, de modo que ele circula nas relações. Por tudo isso, interessa-nos mais pensar sobre relações de poder, do que sobre o "poder" propriamente dito. 
[...] não há algo como "o poder" ou "do poder" que existiria globalmente, maciçamente ou em estado difuso, concentrado ou distribuído: só há poder exercido por "uns" sobre os "outros"; o poder só existe em ato, mesmo que, é claro, se inscreva num campo de possibilidade esparso que se apoia sobre estruturas permanentes. Isto quer dizer também que o poder não é da ordem do consentimento; ele não é, em si mesmo, renúncia a uma liberdade, transferência de direito, poder de todos e de cada um delegado a alguns (o que não impede que o consentimento possa ser uma condição para que a relação de poder exista e se mantenha); a relação de poder pode ser 0 efeito de um consentimento anterior ou permanente; ela não é, em sua própria natureza, a manifestação de um consenso. [...] [o poder] não é em si mesmo uma violência que, às vezes, se esconderia, ou um consentimento que, implicitamente, se reconduziria. Ele é um conjunto de ações sobre ações possíveis; ele opera sobre o campo de possibilidade onde se inscreve o comportamento dos sujeitos ativos, ele incita, induz, desvia, facilita ou torna mais difícil, amplia ou limita, torna mais ou menos provável; no limite, ele coage ou impede absolutamente, mas é sempre uma maneira de agir sobre um ou vários sujeitos ativos, e o quanto eles agem ou são suscetíveis de agir. Uma ação sobre ações. (Foucault, 1995, p. 242-243).

Deleuze e Parnet (1998) ressaltam que as análises de Foucault a respeito das relações de poder e suas heterogeneidades contribuíram para que pudessem ser rompidas as abstrações vazias, a respeito do Estado e da lei, abrindo outros caminhos à análise política. O Estado possui uma face instituída dotada de uma organização estrutural, que chamaremos de aparelho de Estado (Deleuze \& Parnet, 1998). Podemos falar em um Estado estratificado, compartimentado, com instâncias e papéis muito bem definidos, através dos quais vemos operar mecanismos de poder que, por vezes, transfiguram-se em relações de violência e dominação. Todavia, o Estado seria, antes de tudo, o efeito de uma série de processos e investidas dos mecanismos de poder, do que propriamente o foco detentor/emanador "do poder". Ele atua organizando processos que correm no tecido social, fixando territórios e códigos.

[...] o aparelho de Estado é um agenciamento concreto que efetua a máquina de sobrecodificação de uma sociedade. Essa máquina, por sua vez, não é, portanto, o próprio Estado, é a máquina abstrata que organiza os enunciados dominantes e a ordem estabelecida de uma sociedade, as línguas e os saberes 
dominantes, as ações e sentimentos conformes, os segmentos que prevalecem sobre os outros. A máquina abstrata de sobrecodificação assegura a homogeneização dos diferentes segmentos, sua convertibilidade, sua traduzibilidade, ela regula as passagens de uns nos outros, e sob que prevalência. Ela não depende do Estado, mas sua eficácia depende do Estado como do agenciamento que a efetua em um campo social. (Deleuze \& Parnet, 1998, p. 105).

É inegável que o aparelho de Estado, como agenciamento concreto ${ }^{5}$, tem como função política a dominação, a exploração e a mistificação (Baremblitt, 2002), atuando por meio de exclusão e violência. Conforme nos fala Agamben (2004), o Estado de Exceção, outrora considerado uma medida provisória diante de uma excepcionalidade, tem se tornado, cada vez mais, a lógica operacional do governo, apresentando-se como "[...] forma legal daquilo que não pode ter forma legal" (Agamben, 2004, p. 12). Desse modo, acompanhamos o fortalecimento de uma polícia que atua como braço armado do aparelho de Estado, sendo ela a responsável por manter a "ordem" e a norma, muitas vezes à base de tiros e truculência, fatores que corroboram com o processo cotidiano de criminalização dos movimentos sociais. A exceção permite, no extremo, definir quais vidas valem mais e quais vidas podem e devem ser eliminadas, relegadas e/ou marginalizadas para proteger os que merecem viver (Coimbra \& Nascimento, 2009).

“Bom, quando nós começamos a denunciar [as violações de direitos no sistema prisional do Espírito Santo], começamos a tentar um diálogo com o governo, nós não fomos ouvidos. Não fomos ouvidos porque o governador Paulo Hartung nunca recebeu o Conselho Estadual de Direitos Humanos. Ele ficou no governo 8 anos e durante 8 anos ele não abriu nenhuma mesa de negociação pessoalmente, o governo, o governador do Estado, né. Claro que ele mandava os secretários nos ouvirem e que não resolviam nada. Mas ele, pessoalmente, governador do Estado, nós nunca pisamos no Palácio Anchieta durante os 8 anos dele... E ai, nós não nos fazíamos ouvir. Pelo contrário, não é? Quando nós começávamos a denunciar, então nós éramos quem estávamos querendo desestabilizar o governo, provavelmente um de nós queria ser candidato, tínhamos vínculo com o partido $A, B, C$ ou $D$... Não reconhecíamos os avanços do governo, estávamos a serviço de alguém... Essas coisas que a politicagem, não a política, a boa política, mas a política na sua forma mais pejorativa, no Brasil, vem fazendo, muito fácil, né... Sempre deslegitimando o discurso dos direitos humanos". (Entrevista 3) 
Convergindo com tal movimento, vemos uma mídia que relega as práticas de militância a espaços periféricos, usufruindo-se da propagação do sentimento de medo, de periculosidade e de insegurança - úteis mecanismos de controle da sociedade. Não obstante, observamos que o aparelho de Estado tem se apropriado de algumas problematizações colocadas por movimentos sociais, as colocando para funcionar, ou não, de acordo com os interesses em voga.

Isso contribui para que se compreenda o Estado como portador de uma essência, que o definiria como dominador e centralizador. Coimbra e Nascimento (2009) lembram que o fortalecimento de uma lógica binária que define os lugares e os detentores do poder corrobora com os processos de dominação que provém dessa lógica. Trata-se de uma compreensão que atravessa a todos nós, vetores que acompanham os processos de constituição dos sujeitos. Devemos nos indagar acerca dos processos que contribuíram para um entendimento do poder como algo totalizante, localizável, e acerca do modo como viemos a vincular poder e Estado, este sendo a instância máxima daquele. Um poder capaz de sujeitar a todos e, principalmente, certas parcelas da população.

O erro seria dizer: há um Estado globalizante, mestre de seus planos, e que armam suas armadilhas; e então, uma força de resistência que ou vai adotar a forma do Estado, admitindo a possibilidade de nos trair, ou então vai cair em lutas locais parciais ou espontâneas, admitindo a possibilidade de serem, a cada vez, abafadas e derrotadas. O Estado mais centralizado não é de modo algum mestre de seus planos; também ele é experimentador, faz injeções, não consegue prever o que quer que seja [...]. (Deleuze \& Parnet, 1998, p. 118-119).

Consideramos que problematizar noções totalizadoras e generalistas no bojo dos movimentos sociais enseja empreender uma dobra na concepção majoritária de Estado, desmanchando um topos do Estado dicotômico e distanciado, detentor/operador de um poder que deve ser (re)conquistado e partilhado, ideia que eventualmente parece ser investida e fortalecida pelo CDDH e pelos militantes participantes da pesquisa. Trata-se de transversalizar compreensões, dissolver papéis, desnaturalizar práticas.

O desafio que se coloca hoje é como mudar o mundo sem tomar o poder, ou seja, sair da lógica estatal e da identificação entre revolução e controle do Estado. O que as experiências comunistas mostraram é que a mudança não levou à maior liberdade, à autonomia, ao fim das relações de poder, à 
valorização afetual na vida social, ao desenvolvimento social e coletivo, à retomada do corpo e à apropriação da vida, à sustentabilidade ecológica. A idolatria do trabalho, da técnica e do progresso reafirmam-se; a burocratização e a militarização ganham terreno (Oliveira, 2007, p. 35).

Um grande analisador, nesse caso, é a avaliação que os militantes entrevistados fazem sobre a chegada de partidos ditos de esquerda, ou centro-esquerda, a cargos de maior expressão política e, consequentemente, o fato de isso ter proporcionado uma maior abertura dos canais de comunicação entre Estado e movimentos sociais. Grosso modo, consideram que apesar de terem mais espaço e interlocução, muitos problemas continuam, com pautas chegando ao retrocesso, inclusive.

“E eu acho que teve uma evolução espetacular... O movimento se profissionalizou, você tem hoje pessoas que trabalham nas entidades de direitos humanos, o trabalho que era realizado pela militância voluntária hoje é remunerado, as entidades cresceram. [...] Então a formação continua, as reuniões plenárias continuam, a crítica continua, você vê que o Plano Estadual de Direitos Humanos não foi aprovado, algo por que se lutou durante uma década. E aí, o que faltou? A gente não soube fazer as articulações políticas necessárias? E hoje a gente faz essas perguntas, antes a gente empurrava a porta, abria porta ou buscava aliado. Agora nós estamos no poder e não estamos abrindo tantas portas assim. [...] nós conseguimos entrar no Estado e hoje estamos com muito menos espaço, ainda que tenhamos muito mais companheiros ocupando [cargos estatais]... Que contradição é essa? [...] Porque com o governo Lula se abriram muitas portas, políticas voltadas pra mulher, pra assistência, pra saúde. E os movimentos passaram a receber e a gerenciar dinheiro. [...] Ainda que seja um governo do PT, não foram os interesses populares, democráticos, dos trabalhadores que mais mobilizaram. [...] Enfim, acho que a gente começa a se dar conta de que vamos ter que dar um passo atrás pra continuar avançando". (Entrevista 1)

“[...] primeiro era negativa desse Estado, né. Não tinha jeito. Mas, depois a chegada no poder é um negócio complicado... [...] E aí, eu acho que o partido erra muito, o partido tem que ser um instrumento, o seu dirigente tem que fazer essa leitura, mas também dar os elementos para que este filiado, militante, 
que tá lá na ponta, ele possa compreender esse chamado tripé, né, da institucionalidade, dos movimentos sociais, da luta política, né. Então, e aí se fazia uma confusão danada porque tirou bons quadros dessa militância, do protagonismo dessa luta popular e leva pros governos. Ali tem uma confusão, né. [...] A nossa contradição tá exatamente... Ela acentua com a chegada do governo Lula, né. Ela acentua com isso, porque primeiro, assim, todos nós tínhamos uma expectativa enorme naquele governo. Alguns votaram 4 vezes no Lula". (Entrevista 2)

\section{Estado governamentalizado}

Com o intuito de apontar outras vias à compreensão tradicional acerca do Estado, convocamos alguns conceitos-ferramentas propostos por Michel Foucault ao longo de sua obra. Acreditamos que produzir fraturas no entendimento hegemônico de Estado é um dos aspectos prementes à oxigenação das práticas de militância, já que entendê-lo como objetivo último das lutas populares, como alvo da tomada de poder que só poderia ser levada a cabo pelos movimentos sociais, não mais dá conta de absorver toda a complexidade que atravessa a vida.

Foucault (1995) nos fala que, a partir do século XVI, desenvolveu-se uma nova forma política das relações de poder, com a constituição dos Estados Nacionais na Modernidade envolvendo grande mudança nas relações sociais. Outro diagrama de forças estava se forjando e é com base na análise desse processo histórico que Foucault (2008) aponta a passagem das sociedades de soberania para as sociedades de governo. Ele busca decompor os diferentes vetores que atuam nessa transição e, partindo do aparecimento da população como problema, destaca alguns processos preponderantes ao que denomina governamentalização do Estado, momento em que as técnicas de governo passam a ser consideradas imanentes ao aparelho estatal.

O período feudal, marcado pelas sociedades de soberania, apresentava um diagrama de relações de poder que operava pela prática de "fazer morrer ou deixar viver". O rei destinava toda sua atenção e zelo ao território, de modo que Ihe interessava cuidar de seu feudo, expandindo e protegendo suas fronteiras contra invasores, salteadores ou qualquer súdito que ameaçasse seu domínio sobre o território em questão. Aos habitantes que o ocupavam, o rei tratava de deixá-los viver e a vida assumia, dessa maneira, uma forma de indulgência. Porém, mediante qualquer perigo que atentasse contra a supremacia do rei sobre seu quinhão, o mecanismo de poder em questão passava a visar à retirada da vida, na medida em que, em 
última instância, o que o soberano podia fazer para manter sua hegemonia era matar.

Ao final da Idade Média, a circulação de pessoas, a intensificação do comércio, os problemas com epidemias e escassez alimentar passam a compor um processo por meio do qual a questão populacional vai ganhando visibilidade aos olhos do rei e inscrevendo-se como um problema a ser administrado. Dessa maneira, o diagrama do poder passa a investir a vida, ampliando o domínio do território pela ordenação das coisas que estão sobre ele, voltando a atenção para a população e toda a sorte de coisas que a acompanha.

Visando discutir o advento do governo das populações, Foucault (2008) inicialmente busca o auxílio das produções literárias compreendidas entre os séculos XVI e XVIII que versavam sobre a arte de governar - conselhos dados ao príncipe e que abordavam a melhor maneira de governar e manter o controle sobre seu território e as "coisas" que se encontravam nele.

Essa arte de governar esteve durante algum tempo, e antes mesmo nas sociedades medievais, limitada a certos grupos religiosos. A pastoral cristã, ao elucidar a ideia de um governo das almas que conduziria à salvação, funda a problemática das técnicas de governo (Foucault, 1990). Governar nada mais era do que conduzir as condutas dos indivíduos, visando assegurar a salvação individual em outro mundo e também compreendendo a necessidade de se estar preparado para sacrificar-se em prol de seu rebanho (Foucault, 1995). Tratava-se de uma tecnologia de poder, chamada por Foucault de poder pastoral, que se voltava ao cuidado de todos e de cada um, por isso, um poder totalizador e individualizante a um só tempo. A integração da tecnologia do poder pastoral pelo Estado moderno ocidental a partir do século XVI corrobora com o deslocamento do foco do poder, que passa do território - como ocorria nas sociedades de soberania - para a população.

Ocorre, então, o que Foucault (1990) denomina laicização e multiplicação das artes de governar. Multiplicação no sentido em que o problema do governo adentra outros espaços: como governar crianças, pobres, famílias, cidade, estados etc.? Além disso, há uma aproximação entre as técnicas de governo e a figura do Estado.

Já não se trata mais de uma questão de dirigir o povo para sua salvação no outro mundo, mas, antes, assegurá-la neste mundo. E, neste contexto, a palavra salvação tem diversos significados: saúde, bem-estar, (isto é, riqueza suficiente, padrão de vida), segurança, proteção contra acidentes. Uma série de objetivos "mundanos" surgiu dos objetivos religiosos da pastoral tradicional [...]. (Foucault, 1995, p. 238). 
Se nas sociedades de soberania o príncipe mantinha com seu principado uma relação de exterioridade e transcendência - sendo, ademais, o único responsável por conduzi-lo, governá-lo - a formação dos Estados Nacionais inaugura uma pluralidade de práticas concernentes ao governo: o pai que governa uma família, o diretor que governa uma escola, o professor que governa seus alunos, o padre que governa uma Igreja etc. Vemos, então, se interiorizar e escorrer por todos os cantos e espaços técnicas de governo e de gestão da vida.

É no interior do Estado que o pai de família vai governar sua família, que o superior do convento vai governar seu convento, etc. Há, portanto, ao mesmo tempo, pluralidade das formas de governo e imanência das práticas de governo em relação ao Estado [...]. (Foucault, 2008, p. 124).

Vemos demarcarem-se o que Foucault (2008) chama de linhas ascendentes e descendentes, que configuram diferentes formas de governo. No primeiro caso, a pessoa que soubesse governar a si mesma, governando bem, em seguida, sua família e suas posses, por fim, chegaria a governar um estado. A pedagogia garantia a continuidade ascendente dessas formas de governo. No segundo caso, a linha descendente garante que um bom governo do Estado repercutiria, propriamente, na conduta das famílias e, no mais ínfimo movimento, dos indivíduos. Nesse caso, a "polícia" seria a responsável por garantir tal continuidade.

Diferentemente das funções coercitivas que assume na atualidade, a polícia surge, no contexto em questão, como instrumento decisivo na passagem para um Estado de governo, possibilitando a este estabelecer uma relação entre sua ordem interna e o crescimento de suas forças. A polícia era responsável, no século XVII, por “[...] assegurar a manutenção, a higiene, a saúde e os padrões urbanos, considerados necessários para o artesanato e o comércio" (Foucault, 1995, p. 238). A polícia, juntamente à tecnologia diplomático-militar - que se incumbia das relações externas do Estado responsabilizava-se pelo crescimento e manutenção do apogeu dos estados, promovendo a manutenção de uma ordem interna que garantiria o brilho estatal. Para Foucault (2008),

A polícia é o conjunto das intervenções e dos meios que garantem que viver, melhor que viver, coexistir, será efetivamente útil à constituição, ao aumento das forças do Estado. Temos, portanto, com a polícia um círculo que, partindo do Estado como poder de intervenção racional e calculado sobre os indivíduos, vai retornar ao Estado como conjunto de forças crescentes ou a se fazer crescer - mas que 
vai passar pelo que? Ora, pela vida dos indivíduos, que vai agora, como simples vida, ser preciosa para o Estado. [...] fazer da felicidade dos homens a utilidade do Estado, fazer da felicidade dos homens a própria força do Estado (p. 438-439).

Foucault (2008) acompanha a racionalidade ${ }^{6}$ política que guia a experiência moderna e afirma que o que marca as sociedades ocidentais não é o surgimento do Estado e/ou o individualismo fortalecido pela ascensão burguesa, mas sim a correlação entre as técnicas de individualização e totalização (Castro, 2009), que inicialmente percorreram $o$ poder pastoral e se instalaram, posteriormente, na constituição de uma razão de Estado. Ademais, o aparecimento da população como problema e a aproximação entre as técnicas de governo e o Estado são processos intimamente implicados no contexto de formação da biopolítica. A biopolítica, como técnica do governo das populações, retrata-nos o modo como "o problema da vida começa a problematizar-se no campo do pensamento político, da análise do poder político" (Foucault, 1999, p. 288). As técnicas biopolíticas inscrevem-se na problemática de como fazer viver e "viver melhor". Contexto em que a população passa a ser tomada como foco de incidência do poder, instalando-se uma preocupação acerca da "extensão" da vida, que se faz possível por meio de certas intervenções no corpo populacional.

Essa nova tecnologia de poder inaugura a série elencada por Foucault (1999) como sendo 'população - processos biológicos - mecanismos regulamentadores da vida - Estado'. Trata-se de um conjunto biológico e estatal, de bio-regulamentação pela via do Estado. Importante notar que, se o Estado diz da integração dos indivíduos numa totalidade a partir de processos biológicos e de mecanismos reguladores da vida, tal integração se faz exatamente por relações de força desde o interior do corpo social-biológico, e não por uma força "superior" ou soberana. Chamamos a esse poder integrador do Estado Moderno de governo.

Ao contrário, aqui não se trata de impor uma lei aos homens, trata-se de dispor das coisas, isto é, de utilizar táticas, muito mais que leis, ou utilizar ao máximo as leis como táticas; agir de modo que, por um certo número de meios, esta ou aquela finalidade possa ser alcançada (Foucault, 2008, p. 132).

O problema do governo traz consigo questionamentos sobre "como se governar, como ser governado, como governar os outros, por quem devemos aceitar ser governados, como fazer para ser o melhor governador possível?" (Foucault, 2008, p. 118). As práticas de governo investem as vias de constituição do Estado e disso resulta certa imanência dessas práticas em relação ao próprio Estado. 
Foucault empenha-se em mostrar o processo pelo qual o Estado governamentalizou-se, passando a operar de acordo com uma racionalidade política que visa em última instância à manutenção do próprio Estado.

[...] se efetivamente os problemas de "governamentalidade", as técnicas de governo, tornaram-se realmente a única aposta política e o único espaço real da luta e dos torneios políticos, essa "governamentalização" do Estado, todavia, foi o fenômeno que permitiu ao Estado sobreviver. E é verossímil que se o Estado existe tal como existe hoje, foi graças precisamente a essa "governamentalidade" que é ao mesmo tempo interior e exterior ao Estado, já que são as táticas de governo que permitem, a cada instante, definir o que deve ou não ser referido ao Estado, o que é público e o que é privado, o que é estatal e o que é não estatal. Portanto, o Estado em sua sobrevida e o Estado em seus limites não devem ser compreendidos senão a partir das táticas gerais da "governamentalidade" (Foucault, 2008, p. 304).

Contudo, ao mesmo tempo em que se funda uma problematização e todo um conjunto de práticas acerca dos modos de governar, também se vislumbra um questionamento de outro tipo: "como não ser governado?". Foucault (1990) afirma que isso não quer dizer que

[...] na governamentalização, seria opor numa sorte de face a face a afirmação contrária, "nós não queremos ser governados, e não queremos ser governados absolutamente". Eu quero dizer que, nessa grande inquietude em torno da maneira de governar e na pesquisa sobre as maneiras de governar, localiza-se uma questão perpétua que seria: "como não ser governado assim, por isso, em nome desses princípios, em vista de tais objetivos e por meio de tais procedimentos, não dessa forma, não para isso, não por eles. [...] Em face, ou como contra-partida, ou antes como parceiro e adversário ao mesmo tempo das artes de governar, como maneira de suspeitar dele, de o recusar, de o limitar, de lhe encontrar uma justa medida, de os transformar, de procurar escapar a essas artes de governar ou, em todo caso, deslocá-lo, a título de reticência essencial, mas também e por aí mesmo como linha de desenvolvimento das artes de governar, [...] ao mesmo tempo atitude moral e política, maneira de pensar etc. e que eu chamaria simplesmente arte de não ser governado ou ainda arte de não ser governado assim e a esse preço (Foucault, 1990 , p. 3-4). 
Consideramos que a circunscrição do problema também em relação às maneiras de como não ser governado ou, em última instância, como não ser governado de certa forma e sob certos princípios, diz, certamente, de um plano ético por meio do qual podemos produzir desvios, modulações, fazendo disso que estamos sendo uma outra coisa. Plano ético, de resistência, que está em relação constante com os modos instituídos de ser, fazer e governar.

César (2008) ressalta que a questão do governo também nos faz pensar, justamente, na liberdade: como cultivá-la, exercitá-la, fazê-la circular diante de técnicas de poder tão imanentes e que se colocam como mantenedoras e ampliadoras do controle do Estado. Se pensarmos no governo, ou melhor, nas técnicas de governo, como aquilo que nos atravessa e nos constitui, aquilo que compõe nossas próprias práticas e discursos, podemos ver que o aparelho de Estado não é algo estático, transcendental, que não constitui uma entidade, um patamar a partir do qual as forças se consolidam e se exercem.

O que Foucault (2008) busca mostrar, ao explorar a ideia de governo das populações, é que existe uma supervalorização do problema do Estado - fato que encontra ressonâncias no movimento social acompanhado em nosso processo cartográfico -, visto como um monstro frio ou como uma instância que deve ser reduzida a processos básicos, sendo um alvo a atacar ou um espaço privilegiado a se ocupar. De todo modo, Foucault (2008) tenta demonstrar que o Estado "nunca teve essa unidade, essa individualidade, essa funcionalidade rigorosa [...]. O que há de importante para a nossa modernidade, isto é, para a nossa atualidade, não é, portanto, a estatização da sociedade, mas o que eu chamaria de governamentalização do Estado" (p. 144-145).

A governamentalização é um processo ao mesmo tempo interior e exterior ao Estado e atua operando um corte entre aquilo que é de âmbito do Estado e o que não é (Foucault, 2008). Ora, se a questão é de governo e não puramente de Estado, como fazer? Desafios que se colocam diante daquilo que podemos chamar de pulverização das técnicas de governo.

\section{Sociedade de controle, estratégias de governo e movimentos sociais}

Ao convocar Foucault, conseguimos empreender um deslocamento no foco das questões que vislumbramos atravessar a militância do $\mathrm{CDDH}$, que preenchem e ensejam suas lutas: os conflitos - sociais, políticos, raciais, econômicos etc. - suscitados em nossa sociedade contemporânea e capitaneados pelo racionalismo de uma exclusão globalizada, são atualizados pelo Estado e pelas práticas sediadas por ele, todavia o extravasam. Diríamos, acompanhando as contribuições 
foucaultianas, que não se trata de um problema apenas de Estado, mas de governo. Práticas de governo que atravessam a vida, atuando nos processos de constituição de sujeitos. Governar ou, em outras palavras, conduzir condutas, não se trata, pois, de uma particularidade do Estado. Veiga-Neto e Lopes (2007) afirmam que "[...] a modernidade pode ser caracterizada, em termos políticos, pela progressiva estatização tanto das ações de governar quanto das relações de poder" (p. 952) e ainda fazem uma diferenciação entre as palavras governo, que para os autores assume a função de designar todas as ações centralizadoras do aparelho de Estado, e governamento ${ }^{7}$, que serve para designar "[...] todo o conjunto das ações - dispersadas, disseminadas e microfísicas do poder - que objetivam conduzir ou estruturar as ações" (p. 952).

Além disso, o diagrama biopolítico do poder e a governamentalidade inscrevem-se sob a égide de uma sociedade em que o controle se dá a céu aberto, um controle que é, como bem define Deleuze (1992), “[...] de curto prazo e de rotação rápida, mas também contínuo e ilimitado" (p. 224). Na sociedade de controle, acompanhamos a transição de um capitalismo fixado aos territórios para um capitalismo caracterizado por sua liquidez, suas modulações contínuas, desterritorializadas, compatível com a nova ordem da economia neoliberal e globalizada. As leis de mercado se impõem ao funcionamento do aparelho de Estado, de modo que a economia passa a ditar o rumo das ações políticas. Desse modo, fica a cargo de um capital imaterial o controle dos fluxos, os cortes e rupturas que, a todo o momento, incidem nas subjetividades.

As práticas de governo se imiscuem em cada pedaço de nossas existências, de modo que somos nós os condutores dos mecanismos de controle/regulamentação da vida em nossas relações cotidianas, passando a operar por meio da fixação de limites entre o normal e o anormal, entre o aceitável e o inaceitável, produzindo padrões de vida, de conduta, de bem viver. Tudo aquilo que não se encaixa dentro de tais limites torna-se marginal, permanecendo, desse modo, à margem de tudo aquilo que é adotado como modo majoritário de vida. Se, por um lado, as práticas de governo extravasam o aparelho de Estado, na outra ponta do processo podemos notar o modo como os focos de resistência vão sendo capturados, engessados, amortizados.

A sociedade de controle tem a capacidade de absorver rapidamente um infrator como controlador, um inventivo jovem como programador institucional, uma rebeldia em moda, um contestador em político profissional; é a sociedade das retóricas e das incansáveis capturas. Nela se pretende convencer a todos, e de diversas maneiras, sobre a participação democrática em todas as manifestações da vida. Assim é que 
as conhecidas formas de obtenção de consenso político por medo, por omissão ou adesão, agora se expandem para a economia, a cultura, a ecologia, atingem as minorias por meio de pletora de direitos e convocação à participação nas biopolíticas - que sempre emanam dos grupos organizados ou de seletivas manifestações latentes para o Estado, conformando o que Foucault chamou de controle sobre o corpoespécie, a população (Passetti, 2009, p.157-158).

Imanência das práticas de governo em relação ao Estado, biopolítica e mecanismos de controle: é na convergência desses processos múltiplos que movimentos sociais podem ser enredados. Coimbra e Nascimento (2009) ressaltam a necessidade de se pensar as questões referentes aos movimentos sociais no contemporâneo indissociavelmente à inserção destes em uma sociedade de controle neoliberal.

Nesse sentido, é interessante notar como algumas estratégias sediadas pelo aparelho de Estado eventualmente encontram eco no movimento social institucionalizado pelo qual caminhamos. 0 analisador que trata da "chegada ao poder" de partidos de esquerda e centro-esquerda vem acompanhado de uma percepção acerca do aparelhamento também dos movimentos sociais. Questiona-se certo desejo, naturalizado, de disseminação de movimentos sociais "institucionalizados", voltados à captação de recursos para execução de projetos e políticas públicas que carreguem em seu âmago a defesa de direitos. Nesse caminho, vê-se modos de organização mais complexos, que deixam à mostra o fato de que o processo de abertura dos canais de interlocução entre aparelho estatal e movimentos sociais pode envolver, também, um processo de estatização, governamentalização das ações de militância.

“Outras falas me chamaram atenção durante o encontro. Uma delas versava sobre a burocratização da militância. Um jovem que estava lá, ao falar sobre isso, faz uma diferenciação entre militância de conselho e militância de base. No caso, a função de todos que estavam ali deveria ser a de multiplicador de movimentos de base. Qual é a militância que se quer, afinal? A outra fala, na verdade, era um questionamento: 'se o Estado passa a assegurar o direito, como fica a entidade?'".

(Diário de Campo 4, 29/09/2012)

"O problema da representatividade: quem pode falar em nome do $\mathrm{CDDH}$ ? [...] Discutiu-se que não dá para qualquer um falar em nome do $\mathrm{CDDH}$, porque não se sabe o que será dito por 
todos. Às vezes uma pequena coisa dita em desacordo àquilo que a instituição adota como objetivo e/ou diretriz, pode "manchar a imagem" do Centro. E é importante preservar essa imagem. A institucionalização cobra certas coisas. A representatividade é uma delas. ' $\mathrm{O} \mathrm{CDDH}$ tem uma imagem a zelar!'".

(Diário de Campo 7, 16/02/2013)

É desafiador pensar que as práticas de governo e a lógica do controle podem ecoar nos movimentos sociais. A própria compartimentação de "bandeiras" de luta, a sedimentação em grupos identitários retroalimenta a lógica de controle. A fragmentação das lutas acaba abrindo brechas aos processos de dominação e hegemonização sediados pela máquina abstrata do capital.

Mundo dos direitos: a ser negro, índio, mulher, menor, homossexual, deficiente, louco, preso, com muitos outros direitos a participar obrigatoriamente desta sociedade. A sociedade de controle inclui e articula o discurso da exclusão tão pertinente à sociedade disciplinar, e que girou em função da obtenção de direitos ao trabalho, ao sexo, à educação etc. aos diversos fluxos que deságuam em políticas afirmativas, declaração sobre tolerâncias e disseminação da noção de coexistência, entre outros, gerando fusões uniformizadoras que contornam as diferenças (PASSETTI, 2009, p. 160).

Durante nosso processo cartográfico, presenciamos um apego às velhas formas de luta política e de representação. As recentes manifestações mundiais, abordadas na introdução deste artigo, como intercessores ${ }^{8}$, convocam-nos a outrar o olhar a respeito de certa conjugação dos movimentos sociais e das práticas de militância, de modo a estrangeirarmos as experiências engendradas.

[...] ao mesmo tempo em que os "inimigos de fora" nos vencem, começamos também a ser vencidos por nós mesmos e por nossos companheiros. O inimigo também está dentro de nós e ao nosso lado, quando aceitamos, naturalizamos e reificamos diferentes instituições: a organização política, a dureza e a inflexibilidade nossa e de nossos companheiros, uma certa maneira de se fazer política, de se viver a vida. Aprendemos - também através de árduas experiências - que precisaríamos inventar novas formas de se pensar a revolução, a política e a ética, afirmando as diferenças e multiplicidades presentes em nós e no mundo. (Coimbra \& Nascimento, 2009, p. 40). 


\section{Conclusão}

Ao convocar o cenário caleidoscópico propiciado pelas manifestações que correram o mundo, desde o final de 2010, objetivamos fomentar análises de implicações, atentando aos processos de subjetivação que se colocam em curso no contemporâneo.

Como a figura do estrangeiro que, ao visitar-nos, nos coloca um problema, nos arranca de nosso modo habitual e de certo ensimesmamento, podendo produzir o estranho em nós, os protestos mundiais colocaram em evidência novas formas de ajuntamento e novas táticas de luta política. Abriram caminhos para que (re)colocássemos questões sobre o lugar dos movimentos sociais e da militância local no contemporâneo e em sua relação com o aparelho de Estado. Em meio ao inesperado e instantâneo que as manifestações mundiais escancaravam, um questionamento primordial tomava fôlego e se fazia visível: "Como fugir a essa lógica do poder que engole forças vitais, recicla resistências, transforma em mercadoria o que antes era oposição, vampiriza sujeitos e sua capacidade de criar? Onde é possível resistir?" (Oliveira, 2007, p. 3536).

No decorrer do nosso trajeto, evidenciamos práticas que tem sido preponderantes na construção do presente e cuja problematização consideramos fundamental à oxigenação das lutas locais pela garantia de direitos. É nesse sentido que chamamos a atenção para a possibilidade de que as novas formas de manifestação e de luta sejam pistas do que estamos em vias de nos tornar, a partir do processo visceral de transformação que nos arranca das formas rígidas e nos impele a outrar práticas, modos e lógicas.

Entendemos a militância como práticas cotidianas de resistência, que escapam a esquemas pré-concebidos e a uma cartilha de condutas preconizadas como inerentes a um fazer-militante. Assim, militância não pode partir de categorias pré-definidas de "conceitos", mas buscar visibilizar a corporeidade que clama/constrói para si como um tempo presente desejante de poros.

As linhas multicores com as quais nos encontramos para tecer a pesquisa apontaram para o eterno flerte dos movimentos sociais com o perigoso, o inesperado, o rompante. Lutas que beiram sempre 0 precipício, dançando no fio da navalha.

\section{Referências}

Agamben, G. (2004). Estado de Exceção. São Paulo: Boitempo, 2004. Baremblitt, G. (2002). Compêndio de análise institucional e outras correntes. Belo Horizonte: Instituto Félix Guattari. 
Barros, L. P., Kastrup, V. (2009). Cartografar é acompanhar processos. In E. Passos, V. Kastrup, \& L. Escóssia (Orgs.), Pistas para o método da cartografia (pp. 52-75). Porto Alegre: Sulina, 2009.

Brasil. Decreto o 6.044/2007. (2007). Aprova a Política Nacional de Proteção aos Defensores dos Direitos Humanos - PNPDDH, define prazo para a elaboração do Plano Nacional de Proteção aos Defensores dos Direitos Humanos e dá outras providências. Brasília, DF: Presidência da República. Recuperado de http://www.planalto.gov.br/ccivil_03/_Ato20072010/2007/Decreto/D6044.htm

Carneiro, H. S. (2012). Apresentação: Rebeliões e ocupações de 2011. In D. Harvey, E. Teles, E. Sader, G. Alves, H. S. Carneiro, I. Wallerstein, \& V. Safatle. Occupy: movimentos de protestos que tomaram as ruas (pp. 7-14). São Paulo: Boitempo, Carta Maior.

Castro, E. (2009). Vocabulário de Foucault - Um percurso pelos seus temas, conceitos e autores. (I. M. Xavier, Trad.). Belo Horizonte: Autêntica.

Centro de Defesa dos Direitos Humanos (CDDH) da Serra. (2003). Quarta Alteração Do Estatuto Social Do Centro De Defesa Dos Direitos Humanos Da Serra - Estado do Espirito Santo. Serra.

César, J. M. (2008). Processos grupais e o plano impessoal: a grupalidade fora no grupo (Dissertação de mestrado, Programa de Pós-Graduação em Psicologia, Universidade Federal Fluminense, Niterói). Recuperado de http://www.slab.uff. br/images/Aqruivos/dissertacoes/2008/J an aina.pdf

Coimbra, C. M. B., Nascimento, M. L. (2009). Movimentos sociais e sociedade de controle. In S. Tedesco, \& M. L. Nascimento (Orgs.), Ética e Subjetividade: novos impasses no contemporâneo (pp. 39-59). Porto Alegre: Sulina.

Deleuze, G. (1991). Foucault. São Paulo: Brasiliense.

Deleuze, G. (1992). Conversações. São Paulo: Editora 34.

Deleuze, G., \& Guattari, F. (1995). Mil Platôs: capitalismo e esquizofrenia. Volume 1. Rio de Janeiro: Editora 34.

Deleuze, G., \& Guattari, F. (1997). Mil Platôs: capitalismo e esquizofrenia. Volume 4. Rio de Janeiro: Editora 34.

Deleuze, G., \& Parnet, C. (1998). Diálogos. São Paulo: Escuta.

Foucault, M. (1979). Microfísica do Poder. Rio de Janeiro: Editora Graal.

Foucault, M. (1990). O que é a crítica? [Crítica e Aufklärung] Conferência proferida em 27 de maio de 1978. Bulletin de la Société française de philosophie, vol. 82, pp. 35-63. Recuperado de http://portalgens.com. br/portal/images/stories/pdf/critica. pdf 
Foucault, M. (1995). O sujeito e o poder. Em H. L. Dreyfus, P. Rabinow, Michel Foucault, uma trajetória filosófica: para além do estruturalismo e da hermenêutica (pp. 231-249). Rio de Janeiro: Forense Universitária.

Foucault, M. (1999). Em defesa da sociedade: Curso do Collège de France (1975 - 1976). São Paulo: Martins Fontes.

Foucault, M. (2008). Segurança, território, População: Curso dado no Collège de France (1977 - 1978). Rio de Janeiro: Martins Fontes.

Kastrup, V. (1999). A invenção de si e do mundo: uma introdução do tempo e do coletivo no estudo da cognição. Campinas: Papirus.

Oliveira, L. M. B. (2007). Corpos Indisciplinados: ação cultural em tempos de biopolítica. São Paulo: Beca Produções Culturais Ltda.

Passetti, E. (2009). Sobre sociedade de controle, educação e fluxos. In S. Tedesco, M. L. Nascimento. (Orgs.), Ética e subjetividade: novos impasses no contemporâneo (pp. 156-168). Porto Alegre: Sulina.

Passos, E. Barros, R. B. (2009). Por uma política da narratividade. In E. Passos, V. Kastrup, L. Escóssia. (Orgs.), Pistas do método da cartografia: Pesquisa- intervenção e produção de subjetividade (pp. 150-171). Porto Alegre: Sulina.

Paulino, V. S. (2009). Articulação entre os atores sociais na década de 1980: A constituição do projeto democrático participativo no município da Serra, ES (Dissertação de mestrado, Programa de Pós-Graduação em Política Social, Universidade Federal do Espírito Santo, Vitória). Recuperado de http://web3.ufes.br/ppgps/sites/web3.ufes. br.ppgps/files/Vania $\%$ 20Seidler\%20Paulino.pdf

Pelbart, P. P. (2003). Vida capital: Ensaios de biopolítica. São Paulo: Iluminuras.

Pelbart, P. P. (2013). Anota aí: Eu sou ninguém. Folha de São Paulo. Recuperado de http://www1. folha.uol.com. br/fsp/opiniao/119566-quotanotaai-eu-sou-ninguemquot.shtml

Sousa, E. L. A. (2012). Entrevistar. In T. M. G. Fonseca, C. Maraschin, \& M. L. Nascimento (Orgs.), Pesquisar na diferença: um abecedário (pp. 87-88). Porto Alegre: Sulina.

Veiga-Neto, A. (1995). Michel Foucault e Educação: há algo de novo sob o sol? In A. Veiga-Neto (Org.), Crítica Pós-Estruturalista e Educação (pp. 9-56). Porto Alegre: Sulina.

Veiga-Neto, A., Lopes, M. C. (2007). Inclusão e governamentalidade. Educação e Sociedade, 28, 947-963. Recuperado de http://www.scielo.br/pdf/es/v28n100/a1528100.pdf 


\section{Endereço para correspondência Thalita Calmon Capelini}

Rua Theófilo Costa, 160, apto 205, Ed. Lagoa Juparanã, Jardim Camburi, CEP 29092-010, Vitória - ES, Brasil

Endereço eletrônico: thalitacalmon@yahoo.com.br

\section{Gilead Marchezi Tavares}

Universidade Federal do Espírito Santo

Programa de Pós-Graduação em Psicologia Institucional

Avenida Fernando Ferrari, 514, Goiabeiras, CEP 29075-910, Vitória - ES, Brasil

Endereço eletrônico: gileadmt.2014@gmail.com

Recebido em: 30/08/2015

Reformulado em: 01/06/2016

Aceito para publicação em: 08/06/2016

\section{Notas}

* Psicóloga. Mestre em Psicologia Institucional pelo Programa de Pós-Graduação em Psicologia Institucional da Universidade Federal do Espírito Santo.

** Psicóloga. Doutora em Psicologia pela Universidade Federal do Espírito Santo. Professora Adjunta do Departamento de Psicologia e do Programa de PósGraduação em Psicologia Institucional da Universidade Federal do Espírito Santo. Vitória-ES, Brasil.

1 Tomando emprestado o termo utilizado pelos manifestantes espanhóis - o Movimento dos Indignados, iniciado em 2011, levou a população espanhola às ruas a fim de protestar contra a crise política e econômica que assolava o país -, optamos por chamar a essa onda de protestos ao redor do mundo de 'movimentos de indignação'.

2 Entendemos os movimentos institucionalizados como aqueles que possuem fundação legalizada e funcionam por meio de Organizações Não Governamentais (ONGs), Organizações da Sociedade Civil de Interesse Público (OSCIPs) ou Entidades de Interesse Público formalizadas por CNPJ, por exemplo.

${ }^{3}$ O decreto presidencial 6.044, de 12 de fevereiro de 2007, instituiu a Política Nacional de Proteção aos defensores de Direitos Humanos, estabelecendo os " [...] princípios e diretrizes de proteção e assistência à pessoa física ou jurídica, grupo, instituição, organização ou movimento social que promove, protege e defende os Direitos Humanos, e, em função de sua atuação e atividade nessas circunstâncias, encontra-se em situação de risco ou vulnerabilidade" (BRASIL, 2007). Da Política Nacional de Proteção aos Defensores de Direitos Humanos derivou a criação dos Programas de Proteção que, de acordo com informações presentes no sítio eletrônico da Secretaria de Direitos Humanos da Presidência da República, funciona atualmente nos seguintes Estados: Bahia, Minas Gerais, Espírito Santo, Pernambuco, Pará e Rio de Janeiro. Os Estados do Rio Grande do Sul e Ceará passam por processo de implantação do referido programa. No Espírito Santo, a execução desse Programa é feita pelo CDDH de Serra.

${ }^{4}$ Conforme explicitam Deleuze e Parnet (1998), somos feitos de linhas, sendo elas de naturezas diversas, porém imanentes: as linhas de segmentaridade dura, as linhas flexíveis e as linhas de fuga. Tais linhas correspondem à macro e micropolítica, aos planos molar e molecular, aos processos instituídos e instituintes. "Três linhas, sendo uma linha nômade, a outra migrante, a outra sedentária (o migrante, de modo algum a mesma coisa do nômade). Ou então haveria apenas duas linhas, porque a linha molecular apareceria apenas como oscilando entre os dois extremos, ora levada pela conjugação dos fluxos de desterritorialização, ora relacionada com as acumulações das reterritorializações [...]. Ou então há apenas uma linha, a linha de fuga primeira, de borda ou de fronteira, que se relativiza na 
segunda linha, que se deixa parar ou cortar na terceira" (DELEUZE; PARNET, 1998, p. 160-161).

${ }^{5}$ Deleuze (1991) trata como agenciamento concreto aquilo que Foucault nomeou de instituições disciplinares, que atuam produzindo sujeitos e objetos conformados à racionalidade política do momento histórico. Nesse sentido, Foucault (1995) entende que as instituições devem ser analisadas a partir das relações de poder que as constituem e não o contrário.

${ }^{6}$ Por racionalidade entendem-se certos modos de fazer ou agir, marcados por um caráter histórico-fragmentário (CASTRO, 2009) que resguarda a especificidade de cada tempo. Ao propor o estudo das racionalidades, Foucault volta-se a um estudo das práticas, já que toda prática possui uma racionalidade específica que a sustenta.

7 Neste artigo optamos por falar em governo, com letra minúscula, a fim de diferenciar de Governo - no âmbito Municipal, Estadual e Federal. Por vezes também usamos a terminologia práticas de governo, visando ressaltar a caráter dissipativo e microfísico do mesmo, com base no diagrama de poder em questão.

${ }^{8}$ Os intercessores, de acordo com Deleuze (1992) são essenciais ao movimento de criação. Podem ser pessoas, coisas, livros, animais, acontecimentos. Em suma, "fictícios ou reais, animados ou inanimados, é preciso fabricar seus próprios intercessores. [...] sempre se trabalha em vários, mesmo quando isso não se vê" (p. 156). 